\title{
Joining the dots of land-use and land- cover change in Eastern Africa
}

\author{
Oliver Boles ${ }^{1,2}$, C. Courtney-Mustaphi ${ }^{1,3}$, S. Richer ${ }^{1,4}$ and R. Marchant ${ }^{1}$
}

\begin{abstract}
Past land-cover change in Eastern Africa must be understood with reference to changing economies within complex webs of interacting human populations. Databases of archaeological sites and paleoenvironmental geoarchives help explore interactions of anthropogenic and environmental drivers of landscape evolution.
\end{abstract}

\begin{abstract}
Eastern Africa is characterized by strong gradients of environmental variability and cultural diversity. Environments range from hot and moist coastal regions to isolated frigid alpine areas with glaciers, and from dry deserts to biodiverse moist montane forests (Fig. 1a-d), a diversity that has persisted throughout the Holocene even while particular landscapes have seen considerable ecological variability. Outside densely populated and fast-growing urban areas, rural livelihood strategies today range from fishing to specialist mobile pastoralism and sedentary agriculture, some of which is highly intensive. The last 6000 years have seen most Eastern African communities make the transition to food production, which has been accompanied by industrial developments like iron technology and the emergence of supra-regional trading networks, funda-
\end{abstract} mentally changing how societies interacted with their environments. Intensification and diversification of resource use and demographic expansion into previously unexploited areas wrought considerable changes to land cover, as landscapes were manipulated and ecosystems responded. However, our knowledge of these processes exists largely in terms of discrete points - as study sites rather than landscapes. Moreover, the distribution of these points is both temporally and spatially inconsistent, and only in rare instances can we draw direct empirical links between the archaeological and paleoenvironmental records. As a consequence, enquiry into historical landcover and land-use changes in Eastern Africa requires a multidisciplinary approach that combines Quaternary sciences and archaeology with anthropology, history, ethnography and linguistics.

Synthesizing a diverse range of expertise and data necessitates frequent interactions. Over the past two years, there have been LandCover6k-specific workshops (see Editorial, this issue; Marchant and Rucina 2016) and piggybacked meetings at academic conferences with overlapping themes and researchers. Several workshops and meetings had specific relevance to Tropical Africa and have been crucial platforms for the development of ideas and outputs. A PAGES-supported event in October 2015 at the British Institute in Eastern Africa (BIEA), Nairobi, brought together researchers from Congo, Uganda, Tanzania, Kenya, and Europe, and initiated the organization and collation of datasets that ultimately led to the submission of a 40+ multi-author paper published in Earth-Science Reviews (Marchant et al. 2018).
More recently, the African Archaeology Research Day (AARD), hosted at University of York, UK, on 25 November 2017, was used to showcase archaeological and paleoenvironmental datasets and new mapping products relating to historical land-cover and land-use changes since 6 ka BP (Fig. 2a-d). This presentation marked the beginning of a mapping approach that uses expert consultation and consensus building, based on the underlying synthesized data. These new phases build upon the efforts of collating datasets from the region to examine key changes in land use and land cover over the past 6000 years.

\section{The transition to food production}

Contrary to many other areas of the globe, livestock domestication predates crop cultivation in Africa (Marshall and Hildebrand 2002). From a cradle in the northeastern Sahara, stock-keeping spread south and westwards, reaching northern Kenya some 4500 years ago and likely facilitated by an increasingly drier climate (Gifford-Gonzalez 1998). Advancement into eastern Africa took place within a complex web of interactions crossing ethno-linguistic and economic frontiers; rather than a linear spread, stock-keeping was adopted through a series of expansions and contractions - "fits and starts" (Wright 2013) - as communities experienced and moved through changing social and physical environments. Cultivation,
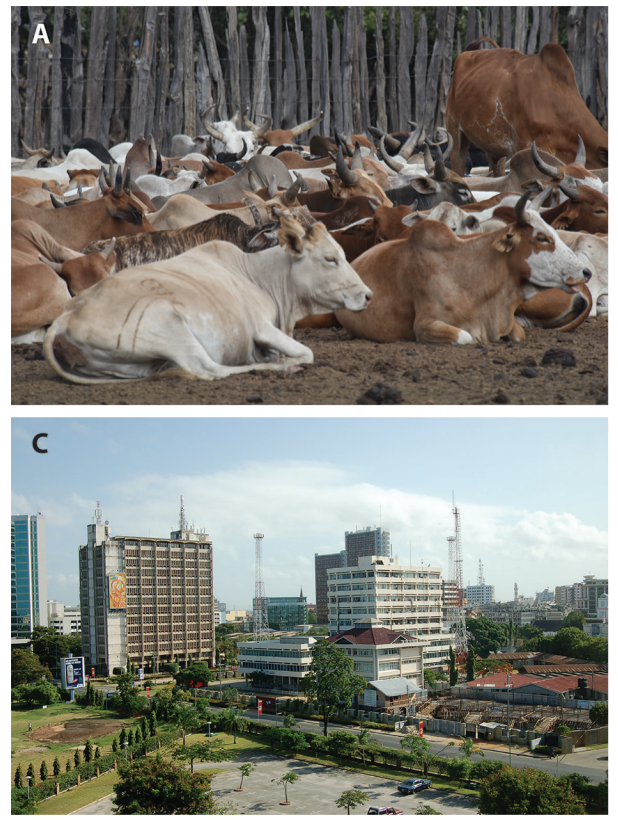

by contrast, first appeared in the region during the late third millennium BP in the highlands of Rwanda and Burundi (Van Grunderbeek 1992). The emergence of farming in the Great Lakes region is generally packaged with iron technology and the spread of Bantu languages; though the exclusivity of this suite can be questioned (e.g. Crowther et al., in press), the timing of these developments coincides with the appearance of language and phrases relating to "fields" and "land clearance" (Schoenbrun 1993).

The ephemerality of pastoralist sites has frequently hindered archaeological investigation (Boles and Lane 2016) and our understanding is largely based on a small number of key locations and observations of faunal remains at non-herder sites, likely obtained through exchange networks. Mapping the distribution of herding therefore relies on inferences drawn from linguistic reconstruction and traditional histories with consideration of environmental conditions. Pastoralism spread southward through the Rift Valley corridor before expanding zonally, which provides a broad framework that can be extended and refined with details such as the drying climate of the late-second millennium BP that facilitated movement into the grasslands of western Uganda (Robertshaw and Taylor 2000). Currently, archaeological sites in southern Tanzania

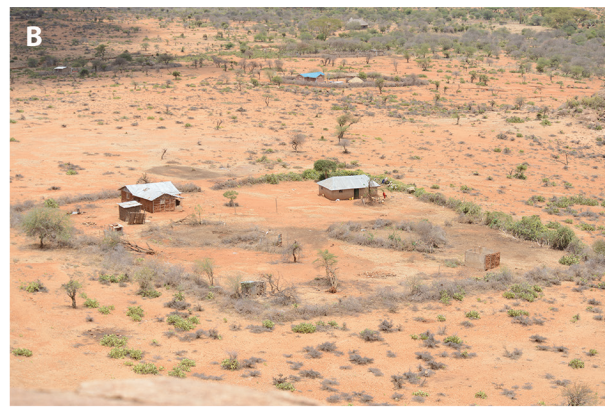

D

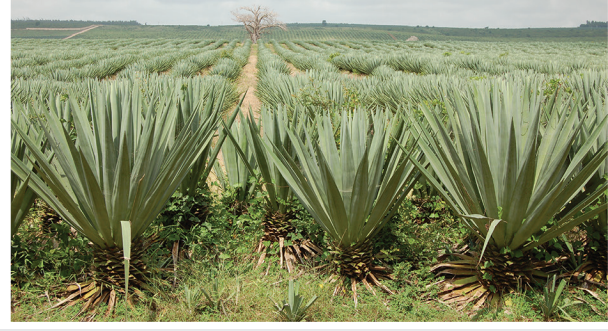

Figure 1: Land uses: (A) pastoralism of grazers; (B) a modern boma with acacia branch outer fence occupied with modern buildings and areas for specific activities; (C) urban land-cover mosaics of Nairobi, Kenya; (D) industrial agriculture of sisal (Agave sisalana Perrine). Images credit: Rob Marchant. 

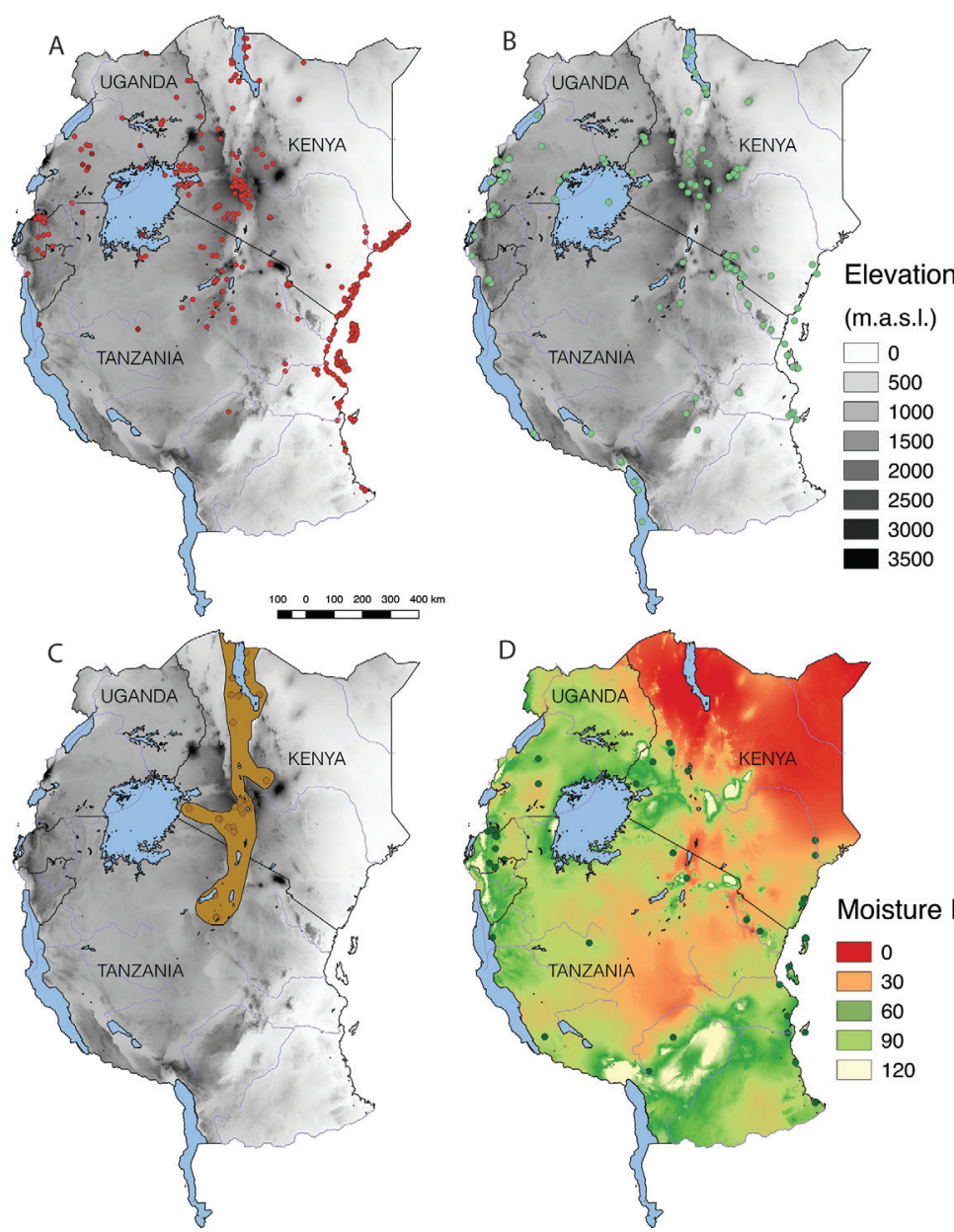

Figure 2: (A) map of Eastern Africa showing the locations of archaeological sites in the database, base-map ASTER DEM (JPL-NASA, 2018); (B) locations of paleoenvironmental geoarchives; (C) possible distribution of pastoralism at $3000 \mathrm{BP}$, based on site distribution and first stage of consensus building; (D) agricultural sites in database, basemap showing moisture index (precipitation relative to potential evapotranspiration) AFRICOVER (FAO 2018).

are rare, yet evidence that pastoralism had reached Southern Africa by the early second millennium BP (Marshall and Hildebrand 2002) requires us to consider that area in our distribution models.

Cultivation is perhaps slightly easier to trace, even if direct tangible evidence is often lacking. We can be confident that crop cultivation first appeared in the region when Bantu farming communities moved from the Congo Basin into the Great Lakes Highlands. These communities are tracked by a close association with pottery styles that eventually reached the eastern shore of Lake Victoria and beyond (Lane 2004). In the last 500 years or so, "islands of intensive agriculture" emerged (Widgren and Sutton 2004); locations such as Engaruka in northern Tanzania evidence technological innovations like terracing and irrigation systems (Stump 2009). As well as indigenous African domesticates like finger millet (Eleusine coracana) and sorghum (Sorghum bicolor), new crops like rice (Oryza sativa) and later, corn (Zea mays) arrived through trading portals on the Indian Ocean coast and changed the agricultural landscape, enabling farmers to exploit new environmental spaces.

\section{Disentangling land use and land cover}

Archaeological research has been spread unevenly across Eastern Africa, with large swathes subject to little or no investigation while other areas - such as the Central Rift
Valley and the Swahili Coast - have been intensively studied. Predictably, this tends to reflect modern population distributions and accessibility. There is, however, reason to suspect that unevenness reflects past population distributions; plotting site locations above a basemap showing modern moisture index (ratio of annual rainfall and potential evapotranspiration; Fig. 2d) suggests past preferences towards the same amenable climatic zones where populations and regional economies are focused today. This is most apparent with respect to sites with evidence of crop cultivation, consistently located in certain zones with more reliable water distribution, such as lake or river basins, or moist highlands. This provides a useful parameter for interpreting between data-points. In conjunction with broader land-cover patterns evidenced in paleoenvironmental records, we can begin to disentangle the probable from the possible spreads of various land-use activities.

Besides the current database of $360+$ archaeological sites (see supplementary data in Marchant et al. 2018), we have assembled records from $150+$ paleoenvironmental geoarchives that represent the collated evidence of land-cover change over the late Holocene available from lake and marine sediments, swamp and peat deposits, glacial ice, and other sources such as tree-ring and coral growth records. As with the archaeology, the coverage of these records is biased towards certain areas and eco-climatic contexts.

Furthermore, their scale and resolution varies widely: a wetland study of $\delta^{13} \mathrm{C}$ isotopes in the sediments provides information on very local variations in vegetation cover in and around the wetlands, whereas a pollen study from lake sediments can spatially aggregate a vegetation-change signal and include pollen taxa from adjacent mountain ecosystems, riverine forests, savannah, and the wetland itself. The next phase of work for our East Africa working group will explore the spatial coverage of our existing data, and develop land-cover maps for the LandCover6k time intervals (see Editorial, this issue) from which to generate environmental niche reconstructions to delimit land-use classes. We have already begun to record which geoarchives have previously been interpreted as evidencing anthropic influence; we will build on this through Bayesian modeling of radiocarbon dates from the paleoenvironmental and archaeological databases to access patterns of synchroneity in environmental and cultural change. In addition to informing our land-use and land-cover distribution maps, such models will help address questions such as how sedimentation rates might have responded to land-use change. These lines of enquiry will be essential in our assessment of how exactly the landscape of Eastern Africa has been affected by dramatic economic change in the last 6000 years.

\section{AFFILIATIONS}

'York Institute for Tropical Ecosystems, University of York, UK

${ }^{2}$ Department of Anthropology, University of Pennsylvania, USA

${ }^{3}$ Department of Archaeology and Ancient History, Uppsala University, Sweden

${ }^{4}$ Department of Archaeology, University of York, UK

\section{CONTACT}

Oliver Boles: oliver.boles@york.ac.uk

\section{REFERENCES}

Boles O, Lane PJ (2016) Azania Archaeol Res Afr 51: 507-530

Crowther A et al. (in press) Quat Int

FAO (2018) AFRICOVER. Food and Agriculture Organisation of the United Nations. www.fao.org/ geonetwork/srv/en/main.search?title=africover

Gifford-Gonzalez D (1998) J Anthrop Archaeol 17: 166-200 JPL-NASA (2018) ASTER Global Digital Elevation Model. Jet Propulsion Laboratory and NASA. https://asterweb.jpl.nasa.gov/gdem.asp

Lane P (2004) Azania J Brit Inst East Afr 39: 243-264

Marchant R, Rucina S (2016) PAGES Mag 24: 39

Marchant R et al. (2018) Earth Sci Rev 178: 322-378

Marshall F, Hildebrand E (2002) J World Prehist 16: 99-143

Robertshaw P, Taylor D (2000) J Afr Hist 41: 1-28

Schoenbrun DL (1993) J Afr Hist 34: 1-31

Stump D (2009) Azania Archaeol Res Afr 41: 69-94 Van Grunderbeek MC (1992) Azania J Brit Inst Afr 27: 53-80

Widgren M, Sutton JEG (2004) Islands of Intensive Agriculture in Eastern Africa. Ohio University Press, 288pp

Wright DK (2013) In: Baldia MO et al. (Eds) Paleoclimatology: Socio-cultural responses to a changing world. Archaeopress, 1-21 